\title{
6-HYDROXYDOPAMINE LESIONS OF THE NIGROSTRIATAL PATHWAY ALTER THE EXPRESSION OF GLUTAMATE DECARBOXYLASE MESSENGER RNA IN RAT GLOBUS PALLIDUS PROJECTION NEURONS
}

\author{
A. E. Kincaid, * R. L. Albin, S. W. Newman, J. B. Penney ${ }^{*}$ and A. B. Young ++ \\ Departments of Anatomy and Cell Biology and Neurology, University of Michigan, Ann Arbor, \\ MI 48109. U.S.A.
}

\begin{abstract}
In situ hybridization was used to study the effect of 6-hydroxydopamine-induced damage to the midbrain dopaminergic neurons on the level of glutamate decarboxylase mRNA in globus pallidus neurons in the rat. Some animals received an injection of Fluoro-gold in the entopeduncular nucleus or the substantia nigra prior to the 6-hydroxydopamine lesion in order to identify glutamic acid decarboxylase mRNA levels in pallidal neurons that project to one of these targets. Analysis was carried out on a sample of all pallidal neurons as well as neurons that were identified as projection neurons in control and lesioned groups.

The loss of the dopamine-containing neurons in the substantia nigra resulted in significant increases in the percentage of globus pallidus neurons that expressed glutamate decarboxylase mRNA and in the amount of glutamate decarboxylase mRNA per globus pallidus neuron. These increases were noted in a sample of all pallidal neurons, as well as pallidal neurons that were identifed as projecting to either the entopeduncular nucleus or the substantia nigra. In control animals, glutamate decarboxylase mRNA was clearly identified in globus pallidus neurons projecting to the entopeduncular nucleus, indicating that this recently reported projection is at least partially GABAergic.

The results of this study indicate that substantia nigra dopaminergic neurons regulate globus pallidus neurons in the rat, and that removal of the dopaminergic input to the corpus striatum results in a significant increase in the amount of glutamate decarboxylase mRNA in pallidal neurons. The decreased firing rate of pallidal neurons that is seen following the loss of dopamine input appears to be accompanied by an increase in the level of glutamate decarboxylase mRNA in these neurons.
\end{abstract}

The importance of the midbrain dopamine-containing neurons in motor control has been established by the characteristic motor disturbances that occur in Parkinson's disease, a disease that is distinguished by a loss of dopaminergic neurons of the substantia nigra ( $\mathrm{SN}$ ) pars compacta. Loss or blockade of dopamine (DA) input results in a variety of physiological and neurochemical changes in basal ganglia structures. ${ }^{1.8}$ Although much attention has been focused on the striatum, changes have been noted in other basal ganglia nuclei as well. Neurons in the

*Present address: Department of Anatomy and Neurobiol. ogy. University of Tennessee. Memphis, TN 38163 , U.S.A.

†Present address: Massachusetts General Hospital, Neurology Service, Fruit Street, Boston, MA 02114, U.S.A.

tTo whom correspondence should be addressed.

Abhreviations: DA, dopamine; EDTA, ethylenediaminetetra-acetate; EP, entopeduncular nucleus; FG, Fluorogold: GAD. glutamate decarboxylase; GP, globus pallidus; HPLC, high performance liquid chromatography; KPBS, potassium phosphate-buffered saline; MPTP, N-methyl-4-phenyl-1,2,3,6-tetrahydropyridine; 6-OHDA, 6-hydroxydopamine; SSC, sodium citratesodium chloride: SN, substantia nigra; $T H$, tyrosine hydroxylase. rodent globus pallidus (GP; homologous to the primate external GP) demonstrate a decrease in spontaneous neuronal activity and an altered firing pattern, as well as a decrease in GABA receptor binding following an ipsilateral 6-hydroxydopamine (6-OHDA) lesion of the nigrostriatal system. . $^{39,40}$ Similar changes in firing rate and GABA receptor binding have been reported in the external segment of the primate $\mathrm{GP}$ in animals treated with $\mathrm{N}$-methyl4-phenyl-1,2,3,6-tetrahydropyridine (MPTP), a selective neurotoxin that eliminates nigrostriatal neurons. ${ }^{8,32,45}$ These changes suggest an increase in GABA inhibition of pallidal neurons from striatal efferent neurons, which are known to contain GABA and glutamate decarboxylase (GAD), the synthetic enzyme and a marker for GABA. 12.18,26.28.42.54 This hypothesis is consistent with evidence for an increase in striatal cell firing rate and an increase in glutamate decarboxylase mRNA levels in striatal neurons following blockage of DA transmission. ${ }^{28,35,37,49,53}$ Thus, the activity of GP neurons may be regulated by the SN DA input to the striatum, via the striatal input to the GP.

The rodent GP is proving to have more extensive efferent connections with other brain nuclei than 
previously thought. In addition to its reciprocal connections with the striatum, ${ }^{6,33,51}$ the subthalamic nuclcus ${ }^{5.25}$ and the $\mathrm{SN}, 5,29.51$ the $\mathrm{GP}$ reportedly projects to the paraventricular nucleus of the thalamus, ${ }^{55}$ the reticular nucleus of the thalamus ${ }^{21}$ and the cerebral cortex. ${ }^{57}$ Recently the GP has been shown to send a substantial, topographically organized projection to the entopeduncular nucleus (EP; homologous to the primate medial GP. ${ }^{22.24}$ While GABA has been identified as a neurotransmitter of pallidal projection neurons to the subthalamic nucleus and the SN, ${ }^{18.43 .47 .51}$ the identity of the neurotransmitter(s) used in other efferent projections of the GP is not known.

In the first part of this study we tested the hypothesis that GP neurons projecting to the EP are GABAergic by combining in situ hybridization for GAD mRNA with Fluoro-gold (FG) tract tracing. ${ }^{19}$ In addition, using a rodent model for Parkinson's disease we investigated the effect of unilateral 6OHDA lesions on the level of GAD mRNA in pallidal neurons. Some of these animals received a FG injection into the EP or SN prior to the 6-OHDA lesion to identify specific pallidal neurons that projected to one of these targets. Relative levels of GAD mRNA were then measured in a sample of all pallidal neurons in control and lesioned animals, and a subset of measurements was taken from FG-filled neurons to specifically determine the effect of 6-OHDA lesions on pallidal neurons projecting to the EP and the SN.

\section{EXPERIMENTAL PROCEDURES}

\section{Stereotaxic surgery}

Adult male Sprague Dawley rats (Harlan Labs, Indianapolis) (244-398 g) were anesthetized with ketamine/xylazine $(10: 3 \mathrm{ratio}, 1.0 \mathrm{cc} / \mathrm{kg}$, i.p.) prior to receiving an iontophoretic injection of FG (Fluoro-chromes, Englewood, CO; $2.0 \%$ in acetic acid, pH 3.3) into either the EP $(n=13)$ or the SN $(n=8)$. Injection coordinates were taken from the atlas of Paxinos and Watson ${ }^{41}$ and for the EP were: AP, -2.6 to $-2.8 \mathrm{~mm}$; $\mathrm{ML},-3.0$ to $-3.2 \mathrm{~mm}$; DV, -7.4 to $-7.5 \mathrm{~mm}$; for the $\mathrm{SN}$ the coordinates were: $\mathrm{AP},-5.5 \mathrm{~mm}$; $\mathrm{ML},-2.0 \mathrm{~mm}$; DV, -7.5 to $-8.5 \mathrm{~mm}$. The FG injections were made via a glass micropipette with an inside tip diameter of $10-35 \mu \mathrm{m}$ for $8-10 \mathrm{~min}$ using $3 \mu \mathrm{A}$ of current ( $7 \mathrm{~s}$ on, $7 \mathrm{~s}$ off).

Six to eight days later the animals received an injection of the neurotoxin, 6-OHDA, ${ }^{56}$ or vehicle in the SN ipsilateral to the FG injections. Thirty minutes prior to anesthesia with sodium pentobarbitol $(35 \mathrm{mg} / \mathrm{kg}$, i.p.), desipramine $-\mathrm{HCl}$ (Research Biochemicals Inc., Natick, MA; $20 \mathrm{mg} / \mathrm{kg}$, i.p.) was administered to protect noradrenergic neurons. Animals were again placed in the stereotaxic unit and injected in the SN with $8 \mu \mathrm{g}$ of 6 -OHDA (Sigma; $n=13$ ) in $4 \mu 1$ of $0.01 \%$ ascorbate (Sigma) in saline over $8 \mathrm{~min}$. Controls $(n=6)$ were injected with the same volume of vehicle in the $\mathrm{SN}$. The pipette was left in place for $8-10 \mathrm{~min}$ after the injection. After 17-20 days, to allow for complete degeneration of the SN dopaminergic neurons, ${ }^{56}$ the animals were anesthetized and transcardially perfused with $100 \mathrm{ml}$ of $0.1 \mathrm{M}$ sodium phosphate-buffered saline with $0.1 \%$ sodium nitrite, followed by $300 \mathrm{ml}$ of $4 \%$ paraformaldehyde with $0.2 \%$ saturated picric acid in $0.1 \mathrm{M}$ sodium phosphate buffer $(\mathrm{pH} 7.4)$. The brains were removed, postfixed in the fixative for $2-3 \mathrm{~h}$ at $4 \mathrm{C}$ and cryoprotected overnght in 20 " sucrose in $0.1 \mathrm{M}$ sodium phosphate buffer with 3 ". polyethylene glycol. ${ }^{4}$

Tissue preparation and fyrosine hydroxylase immonectoto chemistry

The brains were cut coronally into three blocks contain ing the GP, the midbrain, or the cerebellum. Blocks with the GP or cerebellum were covered with embedding mat rix and stored at $70^{\circ} \mathrm{C}$ until they were cut for in situ hybridization.

Coronal sections from the midbrain block were cut $(40 \mu \mathrm{m})$ on a freezing microtome and processed for tyrosine hydroxylase (TH) immunocytochemistry. These sections were collected sequentially into six vials containing $0.02 \mathrm{M}$ potassium phosphate-buffered saline (KPBS) with $0.01 \%$ sodium azide. Every other section was washed and incubated with a mouse monoclonal antibody against TH (Incstar, Stillwater, MN; 1: 10,000 dilution) for $24 \mathrm{~h}$ at $4 \mathrm{C}$. After washing, the sections were incubated in goat antimouse IgG (Jackson Immunoresearch, West Grove, PA: $1: 100$ dilution) for 1 to $2 \mathrm{~h}$ at room temperature. Sections were washed and incubated in mouse peroxidase antiperoxidase (Jackson Immunoresearch; 1:200 dilution) with $4 \%$ normal goat serum for $1-2 \mathrm{~h}$ at room temperature. After washing, the sections were then placed in freshly made diaminobenzidine tetrahydrochloride in KPBS $(0.125 \%)$ with $0.015 \%$ nickel chloride and $0.06 \%$ hydrogen peroxide. After $5.7 \mathrm{~min}$ this reaction was stopped with five quick rinses of distilled water and the sections were transferred to KPBS. All washes were carried out in KPBS and all incubations were carried out in KPBS with $0.3 \%$ Triton $X$ (Sigma). The sections were mounted on to gel-subbed slides. dehydrated in graded alcohols, cleared in xylene and coverslipped with Permount. Control sections were run simultaneously with either the primary or secondary antibody omitted. The presence and location of midbrain $\mathrm{TH}$. immunoreactive neurons were determined with the aid of a microprojector and a Leitz Dialux microscope. Only those animals with a complete loss of the SN DA cell group, in the case of the experimental group (total $n=6$ ). or those animals with no apparent loss of TH-immunoreactive neurons, in the case of the control group (total $n=4$ ), werc processed for in situ hybridization

In situ hybridization histochemistr!

Sections from the tissue blocks that contained the GP or the cerebellum were cut $(12 \mu \mathrm{m})$ in the coronal plane on a cryostat at $-24^{\circ} \mathrm{C}$ and thaw-mounted onto polyL-lysine-subbed slides $(50 \mu \mathrm{g} / \mathrm{ml})$. These sections were stored at $-70^{\circ} \mathrm{C}$ until processed for in situ hybridization histochemistry.

The mounted sections were washed three times in $0.1 \mathrm{M}$ sodium phosphate-buffered saline and placed in $0.25 \%$ acetic anhydride in $0.1 \mathrm{M}$ triethanolamine $-0.9 \% \mathrm{NaCl}$, $\mathrm{pH} 8$, for $10 \mathrm{~min}$. The slides were then dehydrated in $70 \%$ $(1 \mathrm{~min}), 80 \%(1 \mathrm{~min}), 95 \%(2 \mathrm{~min})$ and $100 \%$ ( $1 \mathrm{~min})$ alcohols, transferred to chloroform $(5 \mathrm{~min})$ and returned to $100 \%(1 \mathrm{~min})$ and $95 \%(1 \mathrm{~min})$ alcohols. The tissue was thoroughly air-dried prior to the incubation in hybridization buffer.

Thirty base oligonucleotide probes complementary to (antisense), or matching (sense) bases 1561-1590 of feline GAD cDNA ${ }^{27,34}$ were synthesized on Applied Biosystems Inc. automated DNA synthesizers at the University of Michigan DNA Synthesis Core Facility. The probes were purified by reverse-phase high performance liquid chromatography (HPLC) using C-4, 300 A columns from Rainin Instrument Corp. Both probes were 3 '-end labeled with $\left[{ }^{35}\right.$ S]ATP by 3 -terminal deoxynucleotidyl transferase using a commercially available kit (NEN/Dupont). The labeled probes were purified using NENSORB (NEN/Dupont) purification cartridges. 
These probes were diluted to $4.6-7.3 \times 10^{5}$ d.p.m. in hybridization buffer containing $50 \%$ formamide, $10 \mathrm{mM}$ Tris $(\mathrm{pH} 8), 100 \mathrm{mM}$ dithiothreitol, $1 \times$ Denhardt's solution $(1 \times$ Denhardt's $=0.02 \%$ polyvinylpyrrolidone, $0.02 \%$ ficoll, $0.02 \%$ bovine serum albumin), $10 \%$ dextran sulfate, $1 \mathrm{mM}$ EDTA and $0.3 \mathrm{M} \mathrm{NaCl}$. Each section was hybridized with $40 \mu 1$ of buffer and covered with a glass coverslip. sealed with rubber cement and incubated for $24 \mathrm{~h}$ at $37^{\circ} \mathrm{C}$ in a humid chamber. Following removal of the coverslips, the sections were washed in $2 \times$ sodium citrate-sodium chloride $(\mathrm{SSC} ; 1 \times \mathrm{SSC}=0.15 \mathrm{M} \mathrm{NaCl}$ and $0.015 \mathrm{M}$ NaCitrate) $(30 \mathrm{~min}), 1 \times \mathrm{SSC}(30 \mathrm{~min})$ and $0.5 \times \mathrm{SSC}(15 \mathrm{~min})$ at room temperature. This was followed by a wash in $0.5 \times \mathrm{SSC}$ at $37^{\circ} \mathrm{C}(60 \mathrm{~min})$ and a wash in $0.5 \times \mathrm{SSC}$ at room temperature $(30 \mathrm{~min})$ after which the slides were drained and air-dried. All solutions, except the alcohols, were made in distilled water treated with diethyl pyrocarbonate $(1 \mathrm{ml} / \mathrm{l})$ and all glassware was either autoclaved or baked to prevent RNAase contamination.

Slides were dipped in photographic emulsion (Kodak NTB-2), stored in light-tight containers at $4^{\circ} \mathrm{C}$ and allowed to expose for 23-26 days. Subsequently they were developed in Kodak D-19 at $18 \mathrm{C}$, counterstained with Cresyl Violet for fluorescence, ${ }^{3}$ dehydrated, cleared with xylene and coverslipped with DPX (Gallard-Schlesinger, Carle Place, NY).

Several controls were used to determine the specificity of the antisense probe. Some sections were (i) treated with RNAase (Sigma; $100 \mu \mathrm{g} / \mathrm{ml}$ in $10 \mathrm{mM}$ Tris- $0.5 \mathrm{M} \mathrm{NaCl}$, $\mathrm{pH} \mathrm{8)}$ for $30 \mathrm{~min}$ at $37 \mathrm{C}$ prior to incubation with labeled probe to remove RNA from the tissue (ii) incubated in hybridization buffer without probe, or (iii) incubated in the same amount of radiolabeled sense-strand probe. These controls tested for (i) specificity of the probe for RNA. (ii) signal due to positive chemography, or (iii) specific hybridization between the probe and its target mRNA that is based on its base sequence and not its physical properties, respectively.

Recently two different forms of the synthetic enzyme GAD have been identified..$^{27}$ These two enzymes have different molecular weights, subcellular locations and affinities for the cofactor pyridoxal-5'-phosphate. ${ }^{23}$ The two synthetic enzymes are known as GAD 6 and $G A D_{07}$ and are encoded by two mRNAs that are the product of two genes. ${ }^{11}$ It has previously been reported that both forms of GAD are found in all brain areas that contain GABA neurons except the GP and the triangular nucleus of the septum, where only $\mathrm{GAD}_{67}$ is found $:^{15}$ however, recently it has been reported that both isoforms of the enzyme are present in the GP. ${ }^{11,31}$ The probes used in these experiments were the same or complementary to a portion of the nucleotide sequence for $\operatorname{GAD}_{67} .2$.

\section{Identification and counting of neurons}

Examination of GP neurons was carried out using a Leitz Laborlux microscope equipped with epifluorescence. Pallidal neurons stained with Cresyl Violet were identified using an $\mathrm{N} 2$ filter block (green excitation; 530-560-nm range), inducing red emission. To view silver grains over these pallidal neurons, indicating the presence of GAD mRNA, a combination of bright-field and fluorescence microscopy was used. With the epiffuorescence light source on, silver grains over these neurons were viewed by slowly increasing the intensity of the bright-field lamp. By balancing the intensity of the two light sources, silver grains were clearly identified over the fluorescent, Cresyl Violet-stained neurons. Only those silver grains directly over the cell body and proximal processes were counted. Background levels were determined for each section by counting the number of silver grains overlying adjacent areas of neuropil in the GP that were the same size as GP neurons. Neurons in the GP that had $5 \times$ the background number of silver grains were considered to contain GAD mRNA. Counts of the number of labeled cells were made at $250 \times$ magnification, and grain counts over individual cells were performed manually at $630 \times$ magnification.

Three to five sections through the GP from each animal were coded so that data analysis was performed without knowledge of the animal's experimental group. Pallidal neurons were identified in dorsal, middle and ventral regions of GP (seven neurons in each area), analysed for the presence of GAD mRNA, and those containing GAD mRNA were examined for the number of silver grains in the emulsion overlying the neurons. Those pallidal neurons with projections to $\mathrm{EP}$ or $\mathrm{SN}$ were identified by the presence of golden granules in their somata and proximal dendrites using a $D$ filter block (wide band UV excitation; 355-425$\mathrm{nm}$ range), inducing green-gold emission from $\mathrm{FG}$. All pallidal neurons that were retrogradely labeled with $F G$ were then analysed for number of silver grains in the overlying photographic emulsion.

Quantitative comparisons were made on sections from two different hybridization experiments. These groups were treated identically except for the amount of radio-labeled probe; one group receiving $4.6 \times 10^{5}$ and the other group receiving $5.2 \times 10^{5} \mathrm{~d}$.p.m. Both control and lesioned sections were processed in each of the two groups. These two hybridization groups were exposed for the same length of time (26 days) and developed under identical conditions. Within either the control group or the lesioned group neurons from the two hybridizations had very similar amounts of label per neuron and very similar, low background levels. Sections hybridized under these conditions were chosen for quantitative analysis because of the excellent signal-to-noise ratio and because the lack of fused silver grains over pallidal neurons made counting of these grains more accurate.

Statistical analysis using a non-parametric Mann Whitney rank sum test compared the mean percentage of GAD mRNA-containing pallidal cells per animal, and the mean hybridization signal per neuron per animal between control $(n=4)$ and lesioned $(n=6)$ groups. The mean percentage of GAD mRNA containing FG-libeled cells per animal and the mean hybridization signal in FG-labeled cells per animal between control $(n=3)$ and lesioned $(n=5)$ groups were compared using the same statistical test.

\section{RESULTS}

Specificity of glutamate decarboxylase in situ hybridization

Following hybridization with the ${ }^{35} \mathrm{~S}$-labeled GAD oligonucleotide probe, label was restricted to the area over neuron cell bodies and was seen only in the regions of the brain that have been reported previously to contain GAD or GAD mRNA using immunocytochemistry or in situ hybridization histochemistry, respectively. ${ }^{7,15,34,36.44,61}$ Areas that were examined and noted to have high levels of GAD mRNA included the GP (Figs 1A, 2A), the reticular nucleus of the thalamus (Fig. IB) and the Purkinje cell layer of the cerebellum. Tissue sections that were incubated in hybridization buffer without probe, or incubated with the labeled sense strand probe (Fig. 2B) did not contain any specific labeling. In addition, RNAase pretreatment reduced specific labeling in all areas. The results of these control procedures indicated that the GAD antisense probe was hybridizing to its target mRNA and that the labeling was not due to positive chemography artifact. 


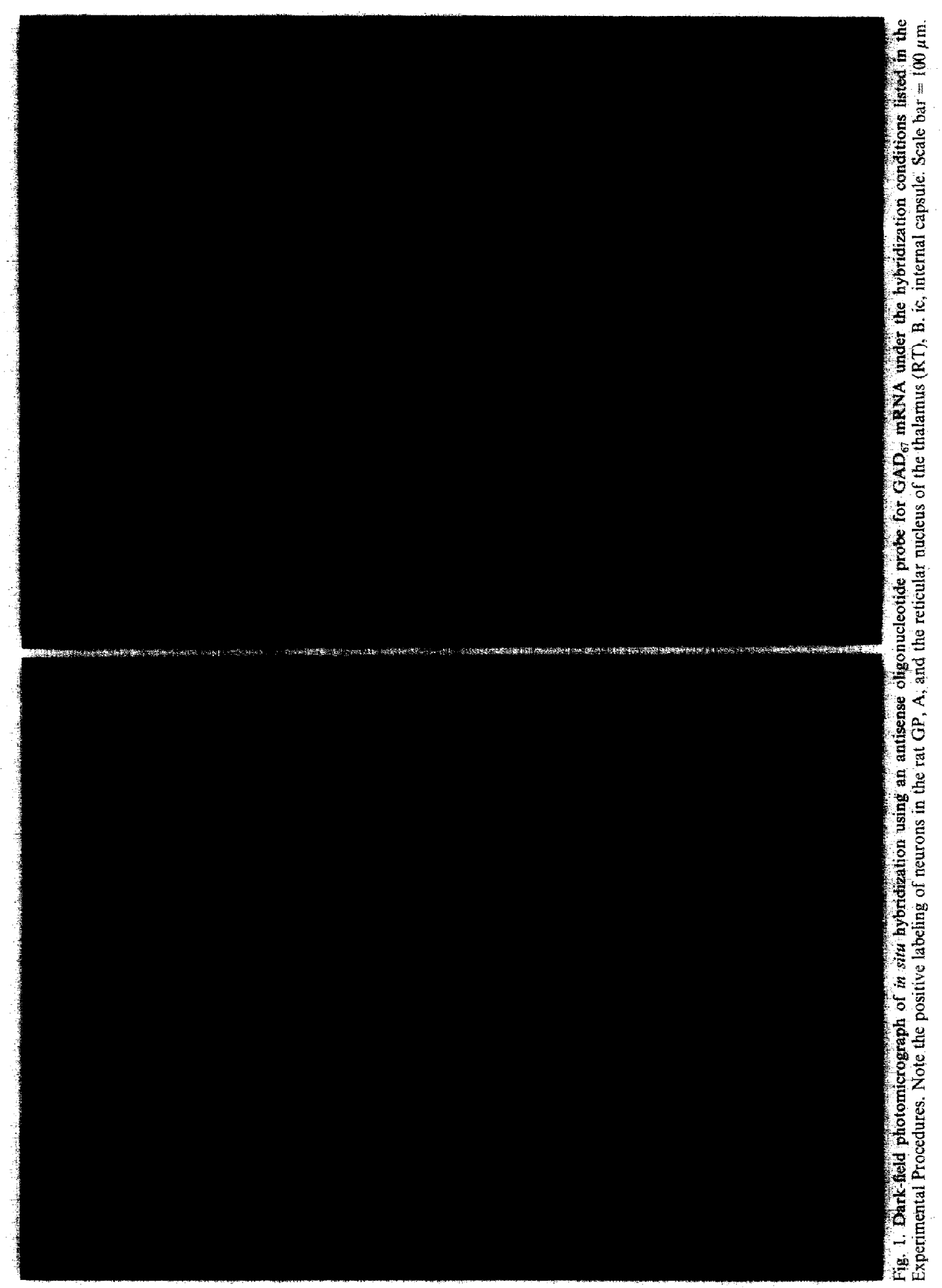




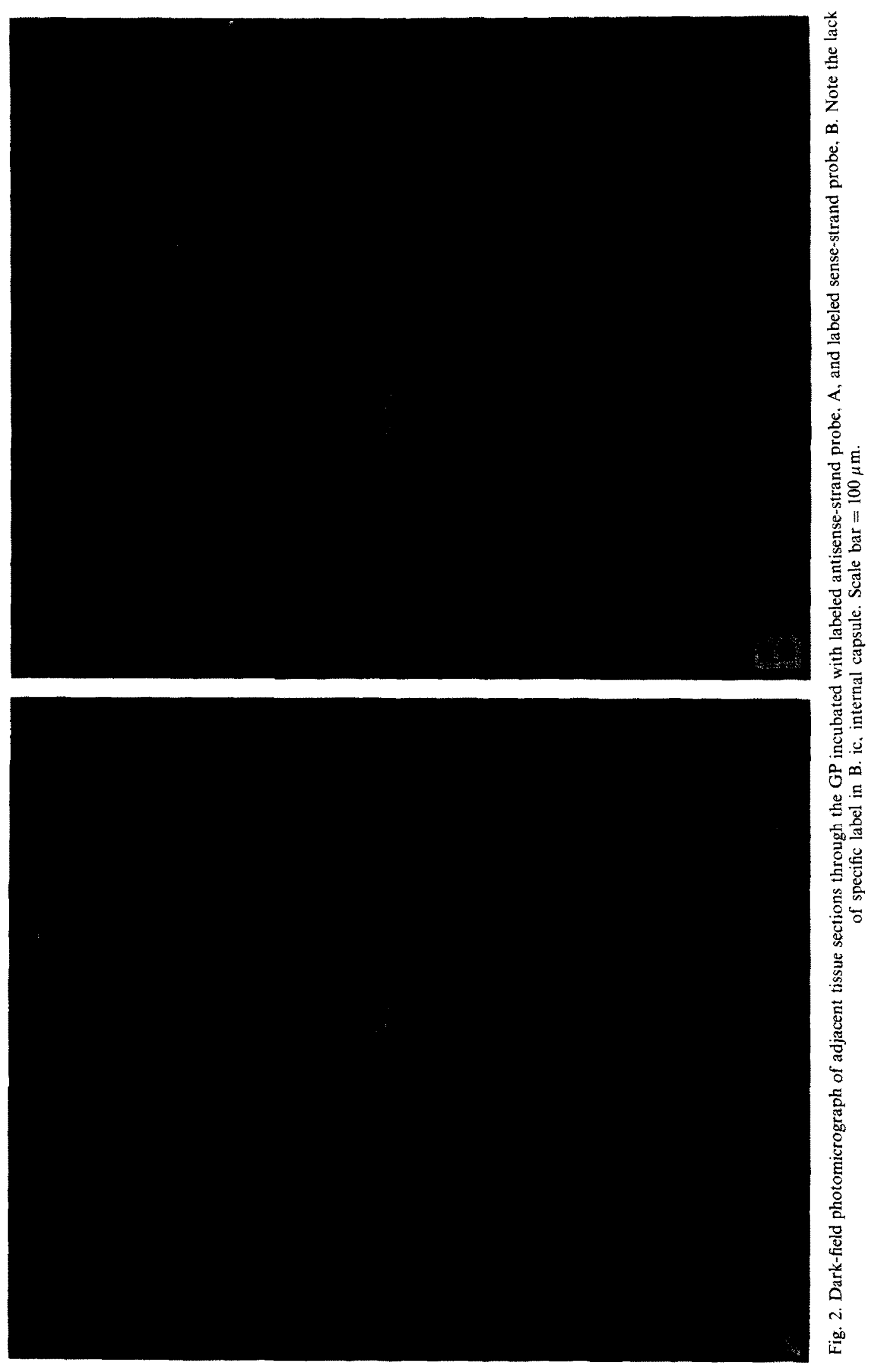




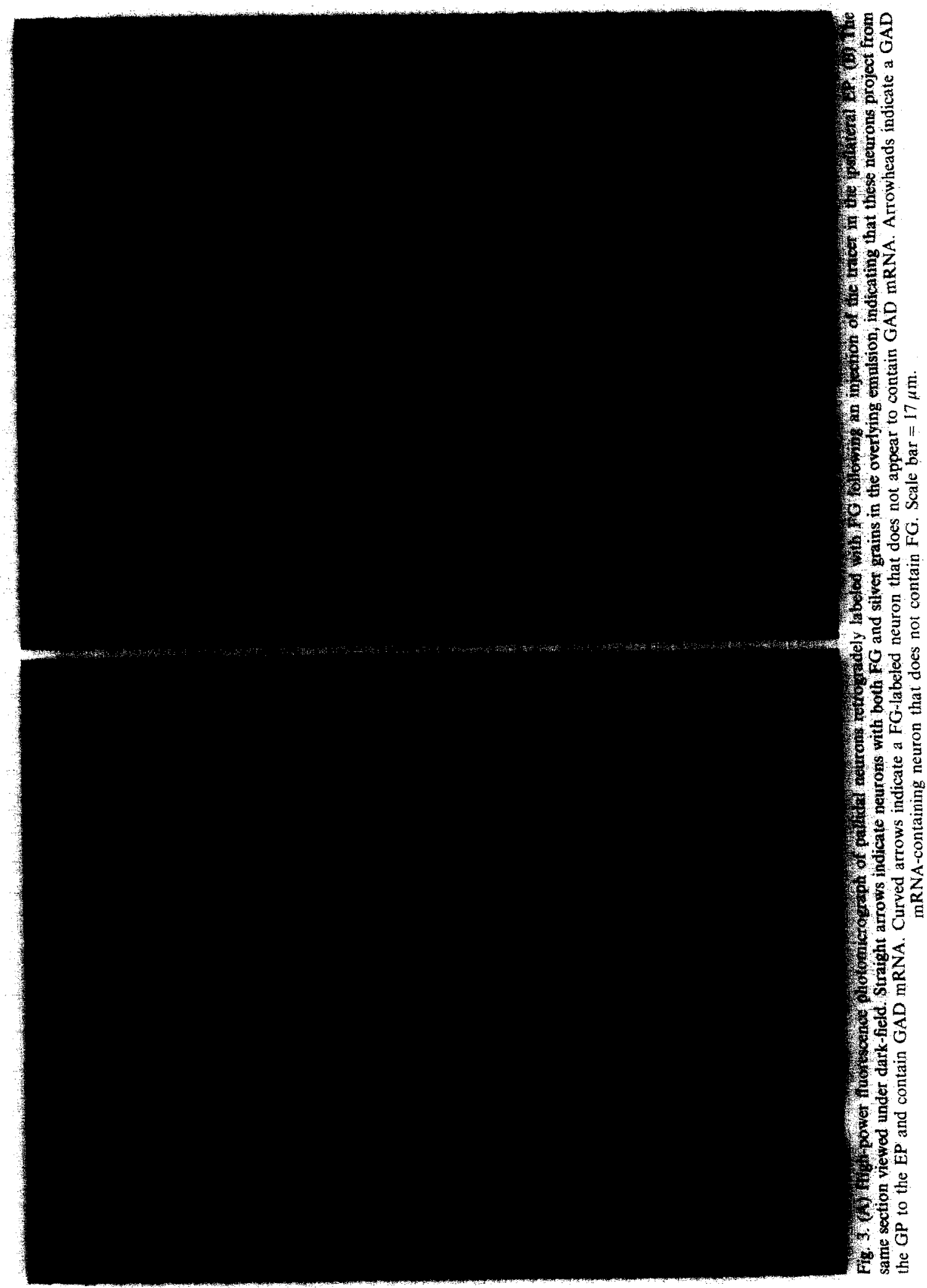




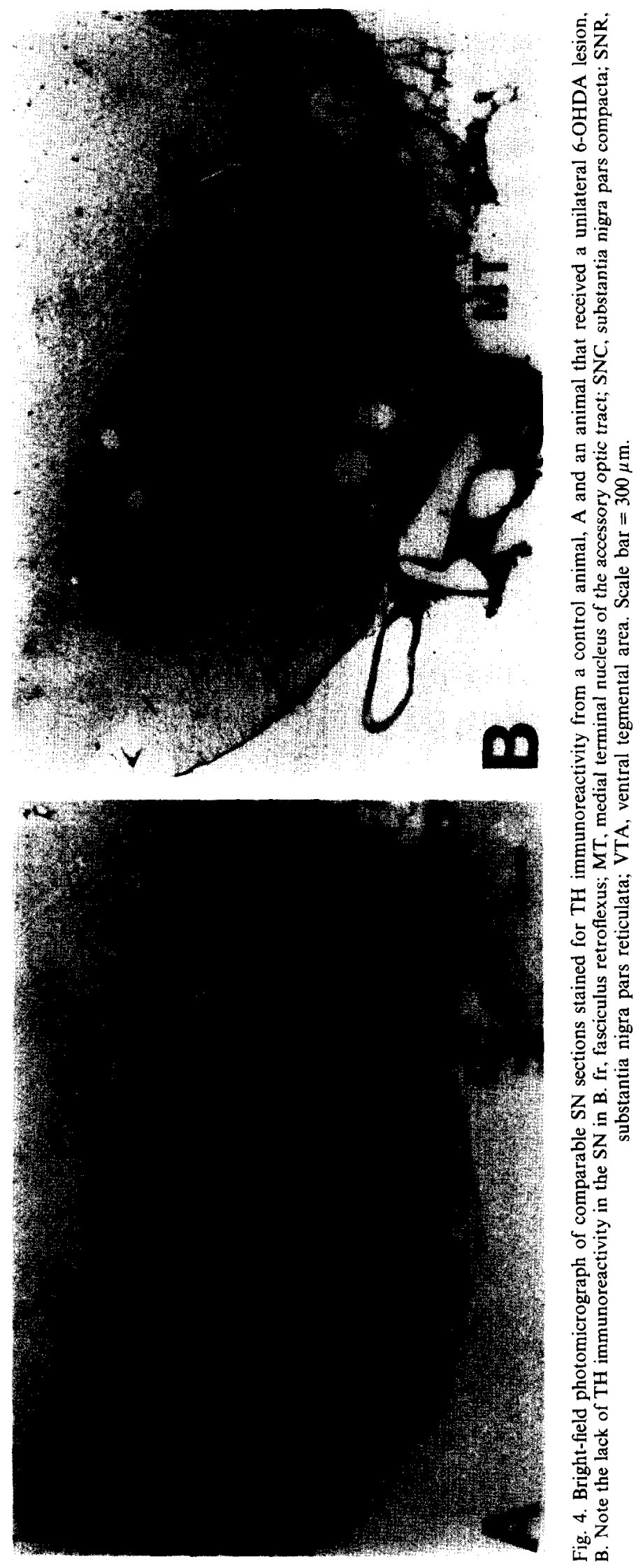




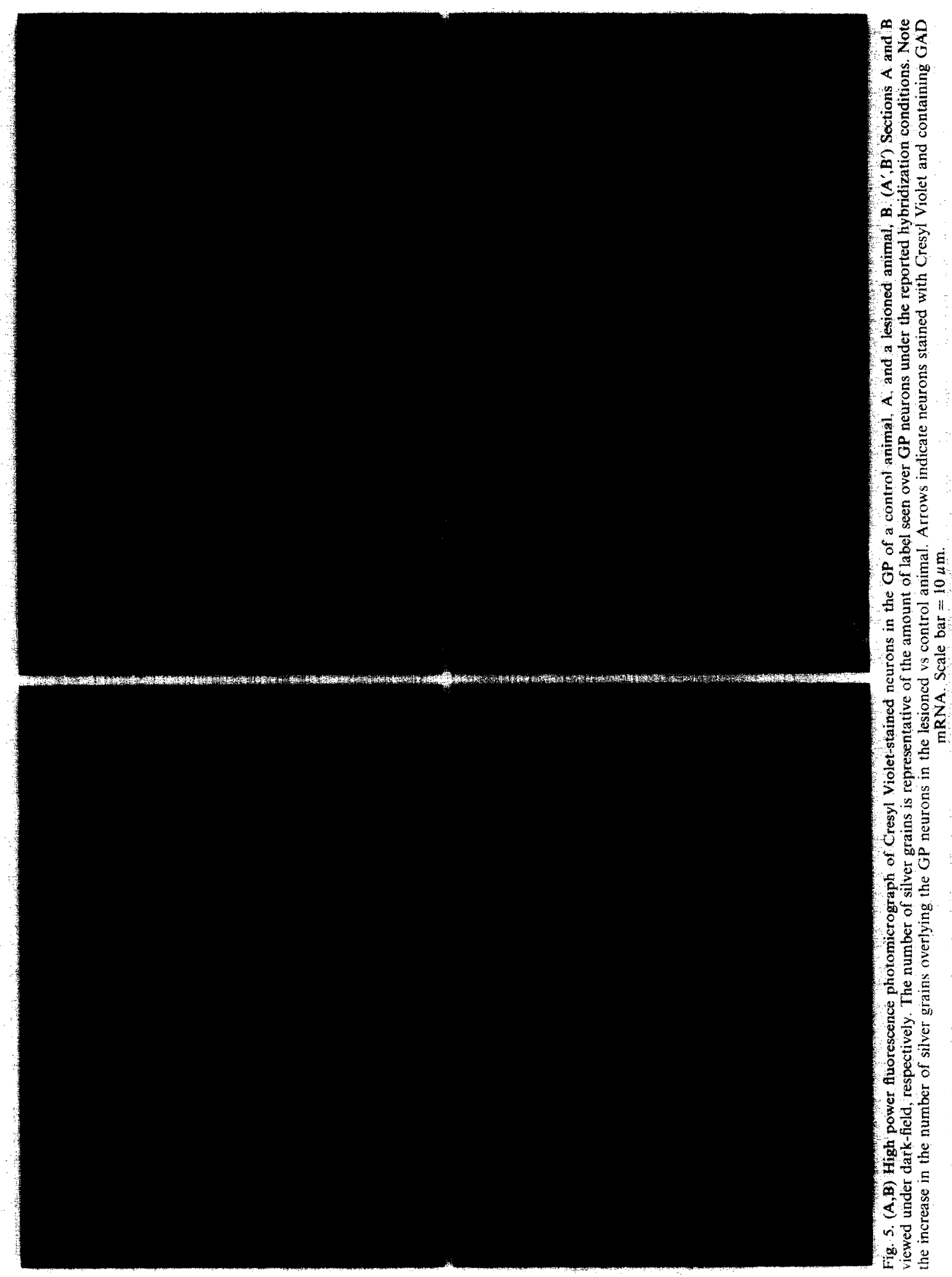




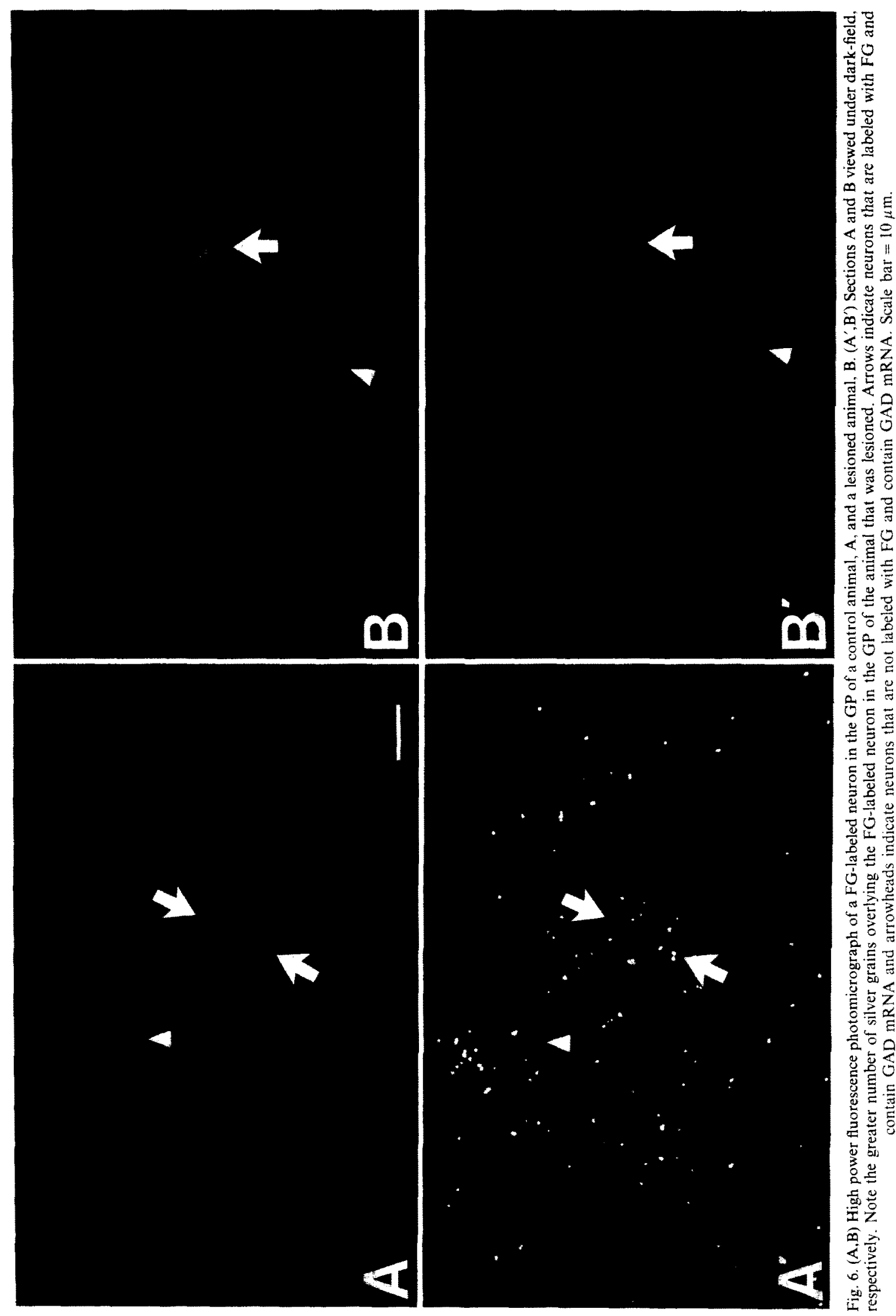


Table 1 .

\begin{tabular}{lcccc}
\hline & \multicolumn{2}{c}{ All GP Neurons } & \multicolumn{2}{c}{ Projection Neurons } \\
& Control & Lesion & \multicolumn{1}{c}{ Control } & Lesion \\
\hline Percentage of GP neurons with GAD mRNA & $67 \pm 5.3$ & $87 \pm 2.9^{*}$ & $56 \pm 1.7$ & $85 \pm 1.8^{*}$ \\
Number of silver grains per neuron & $16 \pm 1.4$ & $31 \pm 3.3^{*}$ & $9 \pm 0.5$ & $16 \pm 1.1^{*}$ \\
\hline
\end{tabular}

Top: percentage of GP neurons that contained GAD mRNA in control and 6-OHDA lesioned animals. Bottom: number of silver grains per neuron in control and lesioned animals. Left column: measurements taken from a sample of all GP neurons (control $n=4$ animals; lesioned $n=6$ animals). Right column: measurements taken from GP neurons that projected to either SN or EP (control $n-3$ animals; lesioned $n=5$ animals). Measurements are mean \pm S.E.M $* P<0.05$.

\section{Glutamate decarboxylase $M R N A$ in pallidal projection neurons}

The FG-containing neurons were easily identified by the presence of golden granules in their somata and proximal dendrites under UV excitation and were noted to be a subpopulation of pallidal neurons (Fig. 3A). The retrogradely labeled pallidal neurons were located in subdivisions of GP topographically related to the injection site, as previously described. ${ }^{24}$ In animals without a lesion in the $\mathrm{SN} 55 \%$ of the FG-containing neurons contained GAD mRNA levels above background ( 42 of 76 neurons from three animals; two with FG injection in EP and one with $F G$ injection in $S N$ ) indicating that some of these projection neurons use GABA as a neurotransmitter (Fig. 3B).

Regulation of glutamate decarboxylase $m R N A$ levels in pallidal neurons

The specificity of the TH antibody used in this experiment to evaluate the 6-OHDA lesions has been demonstrated previously. ${ }^{6}$ Selectivity of the TH immunocytochemistry method was demonstrated by the elimination of all $\mathrm{TH}$ immunostaining in control sections when either the primary or secondary antibody was eliminated from the incubation. The efficacy of the 6-OHDA lesions was demonstrated by TH immunocytochemistry of the mesencephalon. Vehicle injections did not affect $\mathrm{TH}$ immunoreactivity in the mesencephalon (Fig. 4A), whereas animals that received a unilateral 6-OHDA lesion in the midbrain had a complete loss of TH immunoreactivity in neurons of the $\mathrm{SN}$ on the side of the injection (Fig. 4B). TH immunoreactivity in the contralateral SN did not appear to be affected by the neurotoxin.

Animals that received 6-OHDA lesions of the midbrain had a higher pecentage of pallidal neurons expressing GAD mRNA than animals with control injections. The number of pallidal neurons that expressed GAD mRNA increased from an average of $67 \%$ in control animals (316 neurons counted in four animals) to $87 \%$ in the lesioned animals (499 neurons counted in six animals; Table 1). There was also a significant increase in the average amount of GAD transcript per neuron in lesioned animals (31 silver grains/neuron; 430 neurons counted in six animals) compared to controls (16 silver grains/neuron; 218 neurons counted in four animals; Table 1, Fig. 5). Both the increase in the percentage of GP neurons expressing GAD mRNA, and the increase in GAD mRNA level per neuron following the 6-OHDA lesions were statistically significant from control levels using a non-parametric Mann-Whitney rank sum test $(P<0.05$ for both measurements).

Similar relative differences between control and lesioned animals were seen in pallidal neurons that were identified as projection neurons by the presence of FG in their somata and proximal processes. Three of the four control animals had successful $\mathrm{FG}$ injections (two in EP, one in SN) and five of the six lesioned animals had successful $\mathrm{FG}$ injections (three in $\mathrm{EP}$, six in $\mathrm{SN}$ ). Careful analysis revealed no apparent difference hetween animals that received an $F G$ injection into the EP vs the $S N$ with regard to the percentage of projection neurons that contained GAD mRNA, or with regard to the amount of GAD mRNA per neuron in both control and lesioned animals. Because there was no apparent difference, these animals were combined in the same groups for statistical analysis. The number of $\mathrm{FG}$ labeled neurons that expressed GAD mRNA in GP projection neurons increased from an average $56 \%$ in control animals (76 neurons counted in three animals) to $85 \%$ in the lesioned animals (115 neurons counted in five animals; Table 1). There was also a significant increase in the average amount of $\mathrm{GAD}$ transcript per projection neuron in lesioned animals (16 silver grains/neuron; 99 neurons counted in five animals) compared to controls $(8.5$ silver grains/neuron; 42 neurons counted in three animals; Table 1, Fig. 6). This increase in the percentage of GP projection neurons expressing GAD mRNA, and the increase in GAD mRNA level per neuron following the 6-OHDA lesions were also statistically significant from control levels using the Mann-Whitney rank sum test $(P<0.05$ for both measurements)

\section{DISCUSSION}

Evidence provided here indicates that the dopaminergic neurons of the $S N$ regulate the level of GAD mRNA in pallidal neurons, including pallidal neurons that project to the EP or $\mathrm{SN}$, and that removal 
of the DA neurons in the $\mathrm{SN}$ results in an increase of GAD mRNA in GP neurons. The relative proportion of pallidal neurons that contain detectable levels of GAD mRNA, and the amount of GAD mRNA per neuron increased significantly following the removal of the dopaminergic projection to the corpus striatum. These results are consistent with a preliminary report by Soghomonian and Chesselet. ${ }^{52}$ Although it was not possible to determine whether the GP neurons in their study were projection neurons, these authors reported a similar increase in the number of GAD mRNA-labeled pallidal neurons, and an increase in the intensity of label per neuron, in animals that received a 6-OHDA lesion of the SN compared to control animals.

The specificity of the antisense oligonucleotide probe used in this study has been demonstrated previously by detection of a single band of the correct molecular weight for GAD mRNA, using Northern blot analysis, and by a good correlation between regional Northern analysis and in situ hybridization..$^{34}$ Previous experiments have demonstrated a good correlation between the intensity of hybridization signal over neurons and the amount of mRNA in the cells quantified using Northern and dot blot analysis. ${ }^{28.46}$ Consequently, quantitative differences seen in this study in the autoradiographic signal over neurons were interpreted to indicate relative levels of mRNA.

A greater average number of silver grains per neuron was counted in both control and lesioned animals when all pallidal neurons were sampled, as compared to the average number of silver grains recorded when the analysis was restricted to GP neurons that project to the EP or SN (Table 1). It is not known whether this difference in the number of silver grains reflects a real variation in the amount of GAD mRNA in these two populations of pallidal neurons, or if this disparity is an artifact of the techniques utilized in this experiment. Potential sources of artifact include a possible discrepancy between the area of neuronal cytoplasm stained with Cresyl Violet and the degree of filling of the neuronal cytoplasm with FG. It is possible that Cresyl Violet stains more of the GP neuronal cytoplasm than FG fills, resulting in the counting of a greater number of silver grains overlying these apparently larger Cresyl Violet-stained neurons. Another feasible technical source of error may be that the presence of FG in the neuron over the 23-28-day survival period lowers the level of GAD mRNA in these neurons. While these technical considerations may explain the differences noted, it is also conceivable that this discrepancy is real, and that GP neurons projecting to the EP and SN contain less GAD mRNA than other pallidal neurons.

The increase in the number of pallidal neurons expressing GAD mRNA following 6-OHDA lesions of the midbrain may be a result of induction of GAD mRNA in neurons that normally do not express it. Alternatively, this change may reflect an increase in GAD gene transcription or increased stability of GAD mRNA in neurons that normally produce levels of GAD mRNA that are below the sensitivity of this technique. The latter situation appears to exist in the striatum where there are two populations of neurons that express GAD mRNA. The majority of striatal neurons in normal animals express low levels of GAD mRNA while a small percentage express high levels. ${ }^{7.28}$ Following 6-OHDA lesions of the ipsilateral midbrain there is an increase in the proportion of striatal neurons expressing high levels of GAD mRNA. but not an increase in the absolute number of neurons expressing GAD mRNA. ${ }^{2 *}$

Whether the effect of the dopaminergic deafferentation is direct, via decreased dopaminergic innervation of the GP. or indirect, via altered dopaminergic regulation of striatal neurons projecting to the GP remains to be determined. The rat $G P$ receives a modest, direct dopaminergic projection from the SN from collaterals of the nigrostriatal projection. ${ }^{29}$ These fibers provide a potential direct route for dopaminergic regulation of transcription in pallidal neurons. On the other hand, indirect dopaminergic regulation of transcription in pallidal neurons could be mediated by the striatal-pallidal projection, which is extensive and known to contain the neurotransmitters GABA and [Leu]enkephalin. ${ }^{1714.12 .54}$ DA has been shown to regulate both the biochemistry and electrical activity of striatal neurons. Lesions of the nigral dopaminergic cell group are known to result in increases in striatal GAD activity, ${ }^{50.54}$ GAD mRNA levels. ${ }^{28.50 .58}$ and increases in spontaneous neuronal firing rate. ${ }^{35.37 .49}$ These findings suggest a tonic inhibitory action of DA on striatal neurons and a release of inhibition following lesions of the SN pars compacta. These changes in striatal neuronal properties could result in changes "downstream" in the GP.

Based on the results of previous studies, DA regulation of GAD mRNA levels in the GP via the indirect nigral-striatal-pallidal projection is more likely. As mentioned above, there is substantial evidence for increased GABA neurotransmission in striatal-pallidal fibers following SN dopaminergic lesions. This evidence includes a down-regulation of GABA receptor binding in GP and a decrease in pallidal firing rates following 6-OHDA lesions in SN. ${ }^{39,40}$ It is interesting that the increase in pallidal GAD mRNA levels reported here might be associated with a decrease in neuronal firing rate in the same neurons. This is in contrast to a recent study by Litwik et al..$^{3.1}$ who reported a positive correlation between firing rate and transcription rate in GABAergic Purkinje cells of the cerebellum. In this experiment the authors noted an increase in GAD mRNA levels in Purkinje cells following climbing fiber lesions 
and an increase in GAD activity in Purkinje cell axon terminals. Since lesions of the climbing fibers result in an increase in Purkinje cell firing rates, the authors suggest that increased Purkinje cell activity induces transcription of GAD mRNA. ${ }^{30}$ This is similar to the situation in the striatum where striatal neurons demonstrate an increase in firing rate and an increase in GAD mRNA levels following 6-OHDA lesions. The results reported here indicate that the level of GAD mRNA in pallidal neurons is either inversely related to neuronal firing rate, or that firing rate of GP neurons does not affect GAD mRNA levels in the same neurons.

Another possible explanation for changes in GAD mRNA levels in GP neurons is that the amount of message is related to a characteristic of neuronal firing other than firing rate. Previous studies have shown that GP neurons fire in burst discharges and that the bursting pattern of GP neurons is regulated by striatal input. ${ }^{2.48}$ It has also been demonstrated that pallidal bursting increases following the loss of DA input to the corpus striatum. ${ }^{40}$ Since neuronal bursting has been hypothesized to optimize neurotransmitter release, ${ }^{20}$ the increase in GAD mRNA seen in GP neurons in this study may be associated with an increase in GABA release in pallidal target areas.

\section{CONCLUSION}

While it is known that most pallidal neurons are projection neurons and contain GABA, ${ }^{9.13 .35 .42}$ the neurotransmitter in GP neurons that project to the EP has not been identified. Evidence presented here demonstrates that many of these neurons contain GAD mRNA and are therefore GABAergic. It is worth noting that not all pallidal neurons contained GAD mRNA in either the control or lesioned groups in this study, suggesting that some pallidal neurons may not be GABAergic. However, there is the possibility that the lack of GAD mRNA in GP neurons seen in this experiment was due to the hybridization parameters used or that the non-labeled neurons contained the $\mathrm{GAD}_{65}$ isoform.

The existence of a projection from the EP to the GP has recently been described. ${ }^{16}$ Since most EP neurons are known to contain $\mathrm{GABA},{ }^{7,36}$ it appears that this reciprocal projection between the GP and the EP may be an inhibitory loop. Although the functional significance of this relationship is not known, reciprocal connections with other basal ganglia nuclei is a characteristic feature of the GP.

Acknowledgements - The authors wish to thank Lorita Dudus and Kevin Kaatz for their expert technical assistance. This work was supported by NIH NS20629 to S.W.N., NIH NS19613 to A.B.Y. and J.B.P. and the Morphology Core of P-30 Center Grant HD19258.

\section{REFERENCES}

1. Albin R. L., Young A. B. and Penney J. B. (1989) The functional anatomy of basal ganglia disorders. Trends Netrosci. 12, 366-375.

2. Aldridge J. W. and Gilman S. (1991) The temporal structure of spike trains in the primate basal ganglia: afferent regulation of bursting demonstrated with precentral cerebral cortical ablation. Brain Research 543, $123-138$.

3. Alvarez-Buylla A., Ling C.-Y. and Kirn J. R., (1990) Cresyl Violet: a red fluorescent Nissl stain. J. Neurosci. Meth. 33, 129-133.

4. Burgunder J. M. and Young W. S. (1989) Distribution, projection and dopaminergic regulation of the neurokinin B mRNA-containing neurons of the rat caudate-putamen. Neuroscience 32, 323-335.

5. Carter D. A. and Fibiger H. C. (1979) The projections of the entopeduncular nucleus and the globus pallidus in rat as demonstrated by autoradiography and horseradish peroxidase histochemistry. J. comp. Neurol. 177, $113-124$.

6. Chang H. T., Wilson C. J. and Kitai S. T. (1981) Single neostriatal efferent axons in the globus pallidus: a light and electron microscopic study. Science 213, 915-918.

7. Chesselet M.-F., Weiss L., Wuenschell C., Tobin A. J. and Affolter H.-U. (1987) Comparative distribution of mRNAs for glutamic acid decarboxylase, tyrosine hydroxylase, and tachykinins in the basal ganglia: an in situ hybridization study in rodent brain. $J$. comp. Neurol. 262, 125-140.

8. Delong M. R. (1990) Primate models of movement disorders of basal ganglia origin. Trends Neurosci. 13, $281-285$.

9. DiFiglia M. and Rafols J. A. (1988) Synaptic organization of the globus pallidus. J. Electron Microsc. Tech. 10, $247-263$.

10. Erlander M. G., Tillakaratne N. J. K., Feldblum S., Patel N. and Tobin A. J. (1991) Two genes encode distinct glutamate decarboxylases. Neuron 7, 91-100.

11. Esclapez M., Tillakaratne N. J. K., Tobin A. J. and Houser C. R. (1991) Detection of two forms of GAD and their mRNAs in rat brain by immunohistochemistry and non-radioactive in situ hybridization. Soc. Neurosci. Abstr. 17, 416.

12. Fahn S. (1976) Regional distribution studies of GABA and other putative neurotransmitters and their enzymes. In GABA in Central Nervous System Function (eds Roberts E., Chase T. N. and Tower D. B.), pp. 169-186. Raven Press, New York.

13. Falls W. M., Park M. R. and Kitai S. T. (1983) An intracellular HRP study of the rat globus pallidus. II. Fine structural characteristics and synaptic connections of medially located large GP neurons. J. comp. Neurol. 220, 229-245.

14. Feldblum S., Tillakaratne N. J. K., Erlander M. G. and Tobin A. J. (1990) Differential distribution of the mRNAs encoding two forms of glutamic acid decarboxylases in the rat brain: insights on their function. Soc. Neurosci. Abstr. 16,695 .

15. Ferraguti F., Zoli M., Aronsson M., Agnati L. F., Goldstein M., Filer D. and Fuxe K. (1990) Distribution of glutamic acid decarboxylase messenger RNA-containing nerve cell populations of the male rat brain. J. chem. Neuroanat. 3, $377-396$. 
16. Fink-Jensen A and Mikkelsen J. D. (1991) A direct neuronal projection from the entopeduncular nucleus to the globus pallidus. A PHA-L anterograde tracing study in the rat. Brain Res, 542, 175-179.

17. Fonnum F., Gottesfeld Z. and Grofova I. (1978) Distribution of glutamate decarboxylase, choline acetyltransferase and aromatic amino acid decarboxylase in the basal ganglia of normal and operated rats. Evidence for striatopallidal, striatoentopeduncular and striatonigral GABAergic fibers. Brain Res. 143, 125-138.

18. Fonnum F., Grofova I. and Rinvik E. (1978) Origin and distribution of glutamate decarboxylase in the nucleus subthalamicus of the cat. Brain Res. 153, 370-374.

19. Gerfen C. R. and Young W. S. (1988) Distribution of striatonigral and striatopallidal peptidergic neurons in both patch and matrix compartments: an in situ hybridization histochemistry and fluorescent retrograde tracing study. Brain Res. 460, $161-167$.

20. Gonon F. G. (1988) Nonlinear relationship between impulse flow and dopamine released by rat midbrain dopaminergic neurons as studied by in vivo electrochemistry. Neuroscience $24,19-28$.

21. Haber S. N., Groenewegen H. J., Grove E. A. and Nauta W. J. H. (1985) Efferent connections of the ventral pallidum: evidence of a dual striato pallidofugal pathway. J. comp. Neurol. 235, 322-335.

22. Hazrati L.-N., Parent A., Mitchell S. and Haber S. N. (1990) Evidence for interconnections between the two segments of the globus pallidus in primates: a PHA-L anterograde tracing study. Brain Res. 533, 171-175.

23. Kaufman D. L., Houser C. R. and Tobin A. J. (1991) Two forms of the $\gamma$-aminobutyric acid synthetic enzyme glutamate decarboxylase have distinct intraneuronal distributions and cofactor interactions. J. Neurochem. 56, $720-723$.

24. Kincaid A. E., Penney J. B., Young A. B. and Newman S. W. (1991) Evidence for a projection from the globus pallidus to the entopeduncular nucleus in the rat. Neurosci. Lett. 128, 121-125.

25. Kita H. and Kitai S. T. (1987) Efferent projections of the subthalamic nucleus in the rat: light and electron microscopic analysis with the PHA-L method. J. comp. Neurol. 260, 435-452.

26. Kita H. and Kitai S. T. (1988) Glutamate decarboxylase immunoreactive neurons in rat neostriatum: their morphological types and populations. Brain Res. 447, 346-352.

27. Kobayashi Y., Kaufman D. L. and Tobin A. J. (1987) Glutamic acid decarboxylase cDNA: nucleotide sequence encoding an enzymatically active fusion protein. $J$. Neurosci. 7, 2768-2772.

28. Lindefors N., Brene S.. Herrera-Marschitz M. and Persson H. (1989) Region specific regulation of glutamic acid decarboxylase mRNA expression by dopamine neurons in rat brain. Expl Brain Res. 77, 611-620.

29. Lindvall O. and Bjorklund A. (1979) Dopaminergic innervation of the globus pallidus by collaterals from the nigrostriatal pathway. Brain Res. 172, 169-173.

30. Litwak J., Mercugliano M., Chesselet M.-F and Oltmans G. A. (1990) Increased glutamic acid decarboxylase (GAD) mRNA and GAD activity in cerebellar Purkinje cells following lesion-induced increases in cell firing. Neurosci. Lett. 116, $179 \ldots 3$.

31. Mercugliano M., Nguyen A., Feldblum S., Erlander M., Tobin A. J. and Chesselet M.-F. (1991) Comparative distribution of mRNAs encoding two GAD isoforms in output nuclei of the basal ganglia in rats. Soc. Neurosci. Abstr. 17,853 .

32. Miller W. C. and Delong M. R. (1987) Altered tonic activity of neurons in the globus pallidus and subthalamic nucleus in the primate MPTP model of Parkinsonism. In The Basal Ganglia I/ (eds Carpenter M. B. and Jayaraman A.), pp. 415-427. Plenum Press, New York.

33. Nagy J. I., Carter D. A. and Fibiger H. C. (1978) Anterior striatal projections to the globus pallidus, entopeduncular nucleus and substantia nigra in the rat: the GABA connection. Brain Res. 158, 15 29.

34. Najlerahim A., Harrison P. J., Barton A. J. L., Heffernan J. and Pearson R. C. A. (1990) Distribution of messenger RNAs encoding the enzymes glutaminase, aspartate aminotransferase and glutamic acid decarboxylase in rat brain. Brain Res. 7, 317333.

35. Nisenbaum E. S., Stricker E. M., Zigmond M. J. and Berger T. W. (1986) Long-term effects of dopamine-depleting brain lesions on spontaneous activity of type II striatal neurons: relation to behavioral recovery. Brain Res. 398 . $221-230$.

36. Oertel W. H. and Mugnaini E. (1984) Immunocytochemical studies of GABAergic neurons in rat basal ganglia and their relations to other neuronal systems. Neurosci. Lett. 47, 233238.

37. Orr W. B., Gardiner T. W.. Stricker E. M., Zigmond M. J. and Berger T. W. (1986) Short-term effects of dopamine-depleting brain lesions on spontaneous activity of striatal neurons: relation to local dopamine concentration and behavior. Brain Res. 376, 20-28.

38. Ot1ersen O. O. and Storm-Mathisen J. (1984) Glutamate- and GABA-containing neurons in the mouse and rat brain. as demonstrated with a new immunocytochemical technique. J. comp. Neurol. 229, 374-392.

39. Pan H. S., Penney J. B. and Young A. B. (1985) $;$-Aminobutyric acid and benzodiazepine receptor changes induced by unilateral 6-hydroxydopamine lesions of the medial forebrain bundle. $J$. Neurochem. 45, 13961404

40. Pan H. S. and Walters J. R. (1988) Unilateral lesion of the nigrostriatal pathway decreases the firing rate and alters the firing pattern of globus pallidus neurons in the rat. Synapse 2, 650656 .

41. Paxinos G. and Watson C. (1986) The Rat Brain in Stereotaxic Coordinates, 2nd edn. Academic Press, Sydney.

42. Reiner A. and Anderson K. D. (1990) The patterns of neurotransmitter and neuropeptide co-occurrence among striatal projection neurons: conclusions based on recent findings. Brain Res. Ret. 15, 251265.

43. Ribak C. E., Vaughn J. E. and Roberts E. (1980) GABAergic nerve terminals decrease in the substantia nigra following hemitransections of the striatonigral and pallidonigral pathways. Brain Res. 192, 413420.

44. Ribak C. E., Vaughn J. E. and Saito K. (1978) Immunocytochemical localization of glutamic acid decarboxylase in neuronal somata following colchicine inhibition of axonal transport. Brain Res. 140, 315-332.

45. Robertson R. G., Clarke C. A., Boyce S., Sambrook M. A. and Crossman A. R. (1990) The role of striatopallidal neurones utilizing gamma-aminobutyric acid in the pathophysiology of MPTP-induced parkinsonism in the primate: evidence from [ $\left.{ }^{3} \mathrm{H}\right]$ flunitrazepam autoradiography. Brain Res. 531, $95-104$.

46. Romano G. J., Shivers B. D., Harlan R. E., Howells R. D. and Pfaff D. W. (1987) Haloperidol increases proenkephalin mRNA levels in the caudate putamen of the rat: a quantitative study at the cellular level using in situ hybridization. Molec. Brain Res. 2, 33-4l.

47. Rouzaire-Dubois B., Hammond C., Hamon B. and Feger J. (1980) Pharmacological blockade of the globus pallidus-induced inhibitory response of subthalamic cells in the rat. Brain Res. 200, 321329. 
48. Sachdev R. N. S., Gilman S. and Aldridge J. W. (1991) Bursting properties of units in cat globus pallidus and entopeduncular nucleus: the effect of excitotoxic striatal lesions. Brain Res. 549, 194-204.

49. Schultz W. and Ungerstedt U. (1978) Short-term increase and long-term reversion of striatal cell activity after degeneration of the nigrostriatal dopamine system. Expl Brain Res. 33, 159-171.

50. Segovia J., Tillakaratne N. J. K., Whelan K., Tobin A. J. and Gale K. (1990) Parallel increases in striatal glutamic acid decarboxylase activity and mRNA levels in rats with lesions of the nigrostriatal pathway. Brain Res. 529, $345-348$.

51. Smith Y. and Bolam J. P. (1989) Neurons of the substantia nigra reticulata receive a dense GABA-containing input from the globus pallidus in the rat. Brain Res. 493, 160-167.

52. Soghomonian J.-J. and Chesselet M.-F. (1990) Effect of 6-hydroxydopamine (6-OHDA) lesions of the substantia nigra on the levels of glutamic acid decarboxylase (CAD) and preprosomatostatin (SOM) mRNAs in the rat pallidum. Sor Neurosci. Abstr. 16, 1232.

53. Staines W. A., Atmadja S. and Fibiger H. C. (1981) Demonstration of a pallidostriatal pathway by retrograde transport of HRP-labeled lectin. Brain Res. 206, 446-450.

54. Staines, W. A., Nagy J. I., Vincent S. R. and Fibiger H. C. (1980) Neurotransmitters contained in the efferents of the striatum. Brain Res. 194, 391-402.

55. Sugimoto T. and Hattori T. (1984) Direct projections from the globus pallidus to the paraventricular nucleus of the thalamus in the rat. Brain Res. 323, 188-192.

56. Ungerstedt U. (1971) Histochemical studies on the effect of intracerebral and intraventricular injections of 6-hydroxydopamine on monoamine neurons in the rat brain. In 6-Hydroxydopamine and Catecholamine Neurons (eds Malmfors T. and Thoenen H.), pp. 101-127. North Holland Publishing, Amsterdam.

57. Van Der Kooy D. and Kolb B. (1985) Non-cholinergic globus pallidus cells that project to the cortex but not to the subthalamic nucleus in rat. Neurosci. Lett. 57, 113-118.

58. Vernier P., Julien J.-F., Rataboul P., Fourrier O., Feuerstein C. and Mallet J. (1988) Similar time course changes in striatal levels of glutamic acid decarboxylase and proenkephalin mRNA following dopaminergic deafferentation in the rat. J. Neurochem. 51, 1375-1380.

59. Vincent S. R., Nagy J. I. and Fibiger H. C. (1978) Increased striatal glutamate decarboxylase after lesions of the nigrostriatal pathway. Brain Res. 143, $168-173$.

60. Wolf M. E., LeWitt P. A., Bannon M. J., Dragovic L. J. and Kapatos G. (1991) Effect of aging on tyrosine hydroxlase protein content and the relative number of dopamine nerve terminals in human caudate. J. Neurochem. 56, $1191-1200$.

61. Wuenschell C. W., Fisher R. S., Kaufman D. L. and Tobin A. J. (1986) In situ hybridization to localize mRNA encoding the neurotransmitter synthetic enzyme glutamate decarboxylase in mouse cerebellum. Proc. natn. Acad. Sc $i$. 83, 6193-6197. 